\title{
Effect of baffle block configurations on characteristics of hydraulic jump in adverse stilling basins
}

\author{
Ali Abbas ${ }^{1}$, Haider Alwash ${ }^{1}$ and Ali Mahmood ${ }^{2}$ \\ ${ }^{1}$ Building and Construction Engineering Department, University of Technology, Baghdad, Iraq \\ ${ }^{2}$ Rafidain General Company for Dams Construction, Ministry of Water Resources, Baghdad, Iraq
}

\begin{abstract}
The construction of stilling basin with adverse slope change the characteristics of hydraulic jump such as sequent depth ratio, length of jump ratio, length of roller and energy dissipation ratio, consequently the dimensions of stilling basin are changed, also using baffle blocks with different configurations develop these characteristics. In this study different shapes of baffle block (models (A), (B), (C) and (D)) installed in the stilling basins at adverse slopes $(-0.03,-0.045,-0.06)$ in addition to horizontal bed, all these models are tested in the stilling basin to show their effects on the characteristics of hydraulic jump, the experiments applied for the range of Froude number $\left(\mathrm{Fr}_{1}\right)$ between 3.99 and 7.48. The baffle block model (D) showed good results when compared with models (B) and (C), therefore it used with arrangement of (single and double row) and compared with baffle block model (A) at slopes $(0,-0.03,-0.045,-0.06)$ to study the effects of baffle blocks on hydraulic jump when bed slopes are changed. In general using baffle block caused a reduction in sequent depth ratio, length of jump ratio and the length of the roller, but the energy dissipation ratio increased.
\end{abstract}

\section{Introduction}

The hydraulic jump is a phenomenon that occurs when a super critical flow is changed to subcritical flow when the flow obstructed. The rapid change in flow conditions is accompanied by considerable turbulence and dissipation of energy, transferring some of the flow's initial kinetic energy into potential energy [1]. Belanger (1838) predicted the sequent depth ratio $\left(\mathrm{y}_{2} / \mathrm{y}_{1}\right)$ (for horizontal smooth bed) by using the equation of momentum with the assumption of neglected friction [2], and can be written as:

$$
y_{2} / y_{1}=0.5\left(-1+\sqrt{1+8 \mathrm{~F}_{\mathrm{r} 1}^{2}}\right)
$$

Where:

$\mathrm{y}_{2}=$ sequent water depth of a hydraulic jump (m).

$\mathrm{y}_{1}=$ upstream water depth of hydraulic jump (m).

$\mathrm{Fr}_{1}=$ upstream Froude number $=\frac{\sqrt[w_{1}]{\sqrt{\mathrm{g}_{1}}}}{\mathrm{v}_{1}}$

$\mathrm{v}_{1}=$ upstream velocity $(\mathrm{m} / \mathrm{s})$.

$\mathrm{g}=$ gravitational acceleration $\left(\mathrm{m} / \mathrm{s}^{2}\right)$.

The characteristics of hydraulic jump affected when the bed conditions of stilling basin are changed, these bed conditions represented by using adverse slope of stilling basin and availability of appurtenances as baffle block.

Hydraulic jump at the adverse bed slope represent an unstable phenomenon which generates some difficulty in the controlling of it, previous studies showed that the hydraulic jump at adverse slopes greater than $(-0.025)$ is impossible to control, and other studies showed an impossible to keep the jump completely on the adverse slope [4], [5].

The hydraulic jump can be established at $\mathrm{Fr}_{1} \geq 9$ and for $\mathrm{Fr}_{1} \geq 4$ the adverse jump still relatively steady without further tailwater adjustments and for $\mathrm{Fr}_{1}<4$ (especially as the adverse bed slope increased) continuous adjustment was required even the stabilize position was obtained [6].

The friction in the bed of stilling basin would be responsible for the stability of jump on an adverse slope at a minimum value of upstream Froude number $\left(\mathrm{Fr}_{1}\right)$, therefore the presence of artificial roughness, baffle blocks or sills are essential to reach to stable condition [7].

The characteristics of the hydraulic jump that represented by dimensionless parameters such as length of jump ratio $\left(\mathrm{Lj} / \mathrm{y}_{1}\right)$, sequent depth ratio $\left(\mathrm{y}_{2} / \mathrm{y}_{1}\right)$, roller length ratio $\left(\mathrm{Lr} / \mathrm{y}_{1}\right)$ and energy dissipation ratio $\left(\Delta \mathrm{E} / \mathrm{E}_{1}\right)$ 
reduced when the adverse stilling basin is used instead of horizontal bed slope [6], [8], [9].

Stilling basin must be designed perfectly to ensure efficient operating over a wide range of flow. Additional devices may be used to stabilize the jump, reduce the length and height of the jump and increase the energy dissipation. Baffle blocks one of these devices which used to stabilize the jump and dissipate energy as a result of impact action [10].

Baffle block used with different shapes such as cubic and trapezoidal (trapezoidal shape in section), the cubic shape is effective when the best dimensions of height, width, spacing, and the best location in the basin were used. United States Department of the Interior Bureau of Reclamation (USBR) recommended that the corners of baffle block must be not be rounded because the corners are effective in producing of eddies which help in energy dissipation [11].

Previous studies showed that, the model of baffle blocks which have an ability to circulate the jet of water in the vertical transverse direction behave best than others for dissipation of energy, also the rotation in jet of water prevents the jump action to the extent, in this case there is a complete energy dissipation and reduction in the stilling basin length [12].

At adverse bed of stilling basin the specific energy in up stream of hydraulic jump $\left(E_{1}\right)$ and in the end of the hydraulic jump $\left(E_{2}\right)$ can compute by equations (2) and (3) respectively [3].

$$
\begin{aligned}
& \mathrm{E}_{1}=y_{1}+\frac{v^{2}}{2 g} \quad \ldots \ldots \ldots \ldots(2) \\
& \mathrm{E}_{2}=y_{2} \cos \theta+\frac{v^{2}}{2 g}+\mathrm{Lj} \sin \theta
\end{aligned}
$$

Where:

$(\theta)=$ Angle of inclination of bed.

$(\mathrm{Lj})=$ length of the hydraulic jump (m).

The losses in energy due to hydraulic jump compute by the equation:

$$
\Delta \mathrm{E}=\mathrm{E}_{1}-\mathrm{E}_{2}
$$

\section{Experimental work}

The experimental work of this study has been done in the laboratory of fluid mechanics, Building and Construction Department, University of Technology, Baghdad.

The laboratory flume that used were divided into two sections, the first one located in the upstream side of the sluice gate which has a rectangular section with $0.3 \mathrm{~m}$ wide, $0.55 \mathrm{~m}$ deep and $2.30 \mathrm{~m}$ long and the second section located in the downstream side of the sluice gate which has a rectangular section with $0.3 \mathrm{~m}$ wide, $0.3 \mathrm{~m}$ deep and $10.20 \mathrm{~m}$ long.

A plastic platform was installed in the flume to make a different adverse bed slope $(-0.03,-0.045,-0.06)$ in addition to horizontal bed. The platform consists from three parts as shown in Figure (1), the first part of platform represents the stilling basin zone and used to adjust the inclination of the bed slope (adverse and horizontal slopes) which has a length of $1 \mathrm{~m}$, the second part represents a horizontal plane has the same level of end of the first part with a length of $1 \mathrm{~m}$, the third part represents a transition between the level of end of adverse slope and the level of the bed of the flume.

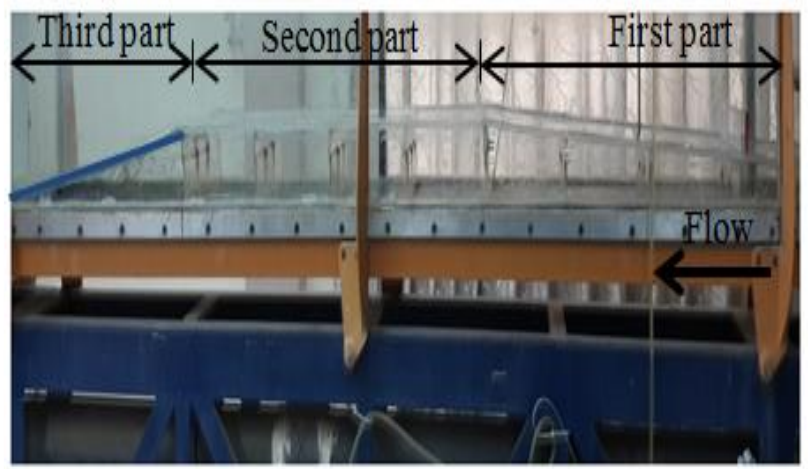

Fig. 1 Platform parts.

The models of baffle blocks that used in the experimental work can be described as the following:

1- Baffle block according to USBR recommendations (Model A) with $50 \mathrm{~mm}$ height and $37.5 \mathrm{~mm}$ wide with $50 \%$ blockage ratio as shown in Figure (2).

2- Baffle blocks with a trapezoidal shape (in plan) were used with 3 models (B, C and D) as shown in Figure (3) and (4).

Model (B) was made with an apex angle of $53^{\circ}$, model (C) with apex angle of $70^{\circ}$ and model (D) with apex angle of $90^{\circ}$, the dimensions of all baffle models summarized in table (1).

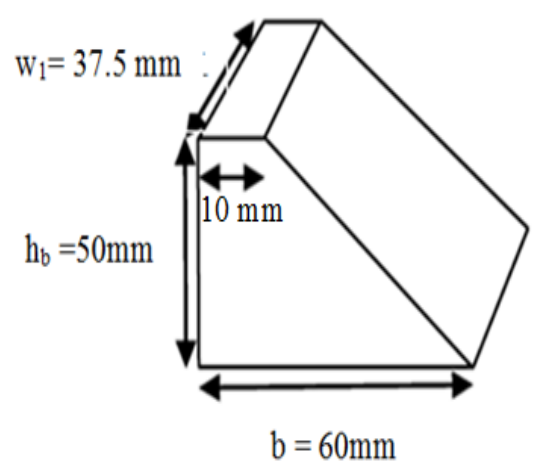

Fig. 2. USBR baffle block (Model A).

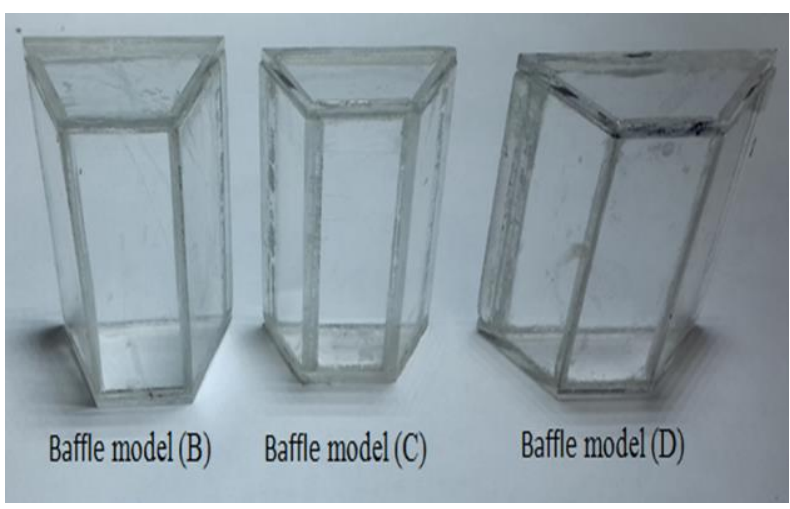

Fig. 3. Shape of trapezoidal baffle blocks. 


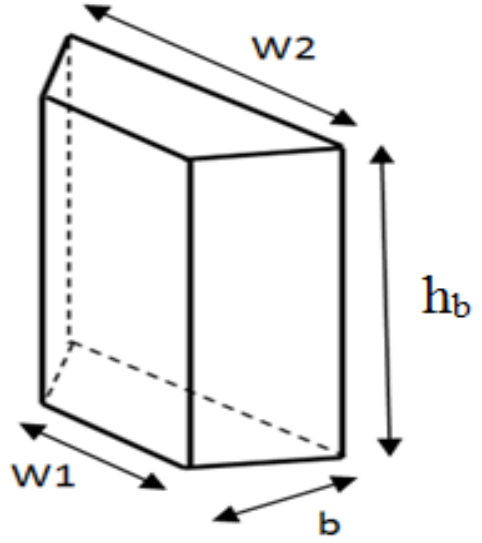

Fig. 4. Shape of trapezoidal baffle block.

Table 1. Dimensions of baffle block models.

\begin{tabular}{|c|c|c|c|c|c|}
\hline Baffle & Height & \multicolumn{2}{|c|}{ Width (mm) } & \multicolumn{2}{c|}{ Length (b) (mm) } \\
\cline { 3 - 6 } & $\left(\mathrm{h}_{\mathrm{b}}\right)$ & $\mathrm{w}_{1}$ & $\mathrm{w}_{2}$ & $\begin{array}{c}\text { Upper } \\
\text { side }\end{array}$ & $\begin{array}{c}\text { Botto } \\
\text { m side }\end{array}$ \\
\hline$(\mathrm{cm})$ & 50 & 37.5 & 37.5 & 10 & 60 \\
\hline$(\mathrm{B})$ & 50 & 20 & 37.5 & 17.5 & 17.5 \\
\hline$(\mathrm{C})$ & 50 & 20 & 37.5 & 12.4 & 12.4 \\
\hline$(\mathrm{D})$ & 50 & 20 & 50 & 15 & 15 \\
\hline
\end{tabular}

Baffle blocks fixed on the platform with a distance $\left(X_{b}\right)$ from the toe of the hydraulic jump, the best stability of hydraulic jump and minimum depth of tailwater occurs when baffle blocks at a location ratio $\left(\mathrm{X}_{\mathrm{b}} / \mathrm{y}_{2}\right)$ $=1.87$, therefore the baffle blocks fixed at a distance $\left(\mathrm{X}_{\mathrm{b}}\right)$ $=0.32 \mathrm{~m}$.

In general, for each experiment the plastic platform installed on the particular slope and the baffle blocks fixed on it (if required). The sluice gate adjusted at a required opening and the flow rate controlled by regulating valve and flow meter.

The hydraulic jump at adverse slope is difficult to be controlled and continually adjusting for the tailgate is essential to reach a stable position. After the free jump is formed and stabilized in its position as shown in Figures (5 to 8), the sequent depth measured by point gage, length of the roller and jump length were measured by measuring tape.

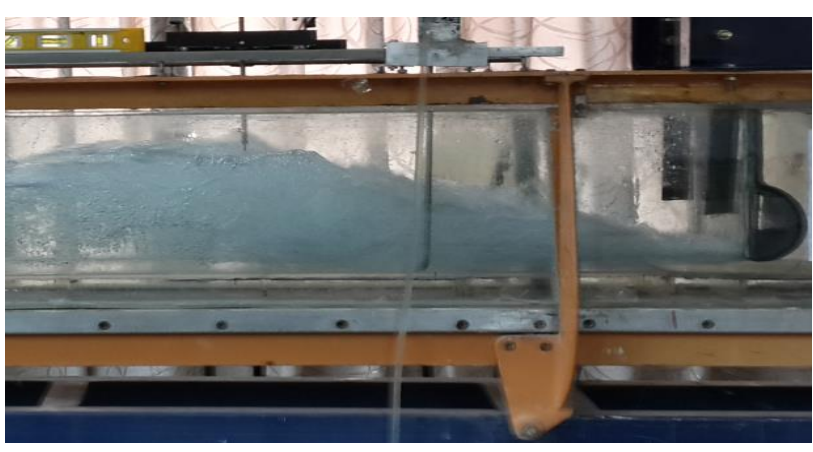

Fig. 5. Hydraulic jump at horizontal bed with single baffle model (A), $\left(\mathrm{Fr}_{1}=5.23\right)$.

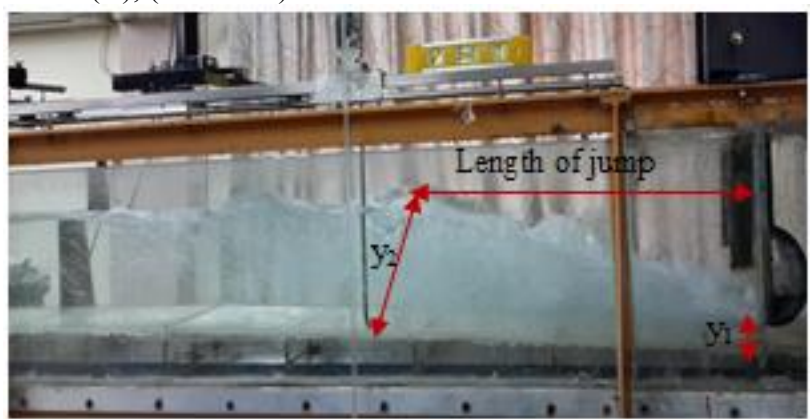

Fig. 6. Hydraulic jump at smooth adverse bed slope (-0.03), $\left(\mathrm{Fr}_{1}=3.98\right)$.

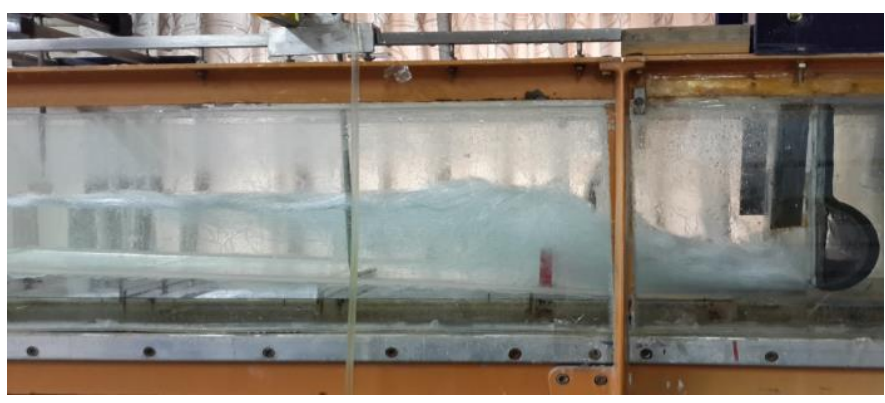

Fig. 7. Hydraulic jump at adverse bed slope (-0.045) with single baffle model (D), $\left(\mathrm{Fr}_{1}=6.43\right)$.

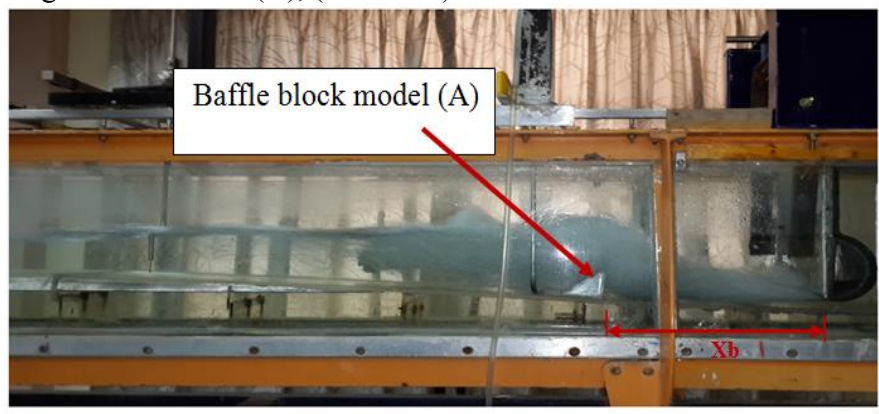

Fig. 8. Hydraulic jump at smooth adverse bed slope (-0.06), $\left(\mathrm{Fr}_{1}=5.83\right)$

\section{Results}

\subsection{Testing of baffle blocks}

\subsubsection{Single row of baffle block}


Baffle block models (A, B, C and D) arranged with a single row and tested on slope (- 0.06) to show any which have good result, experimental data of hydraulic jump on slope (-0.06) with baffle model (D) show a less value for the ratios $\left(\mathrm{Lj} / \mathrm{y}_{1}\right),\left(\mathrm{y}_{2} / \mathrm{y}_{1}\right),\left(\mathrm{Lr} / \mathrm{y}_{1}\right)$ and high value of $\left(\Delta E / E_{1}\right)$ when compared with baffle model (B and $\left.C\right)$ as shown in Figures (9 to 12), therefore baffle block models (A and D) installed on slopes $(0,-0.03,-0.045)$ to study their effect in the characteristics of hydraulic jump when the bed slope is changed.

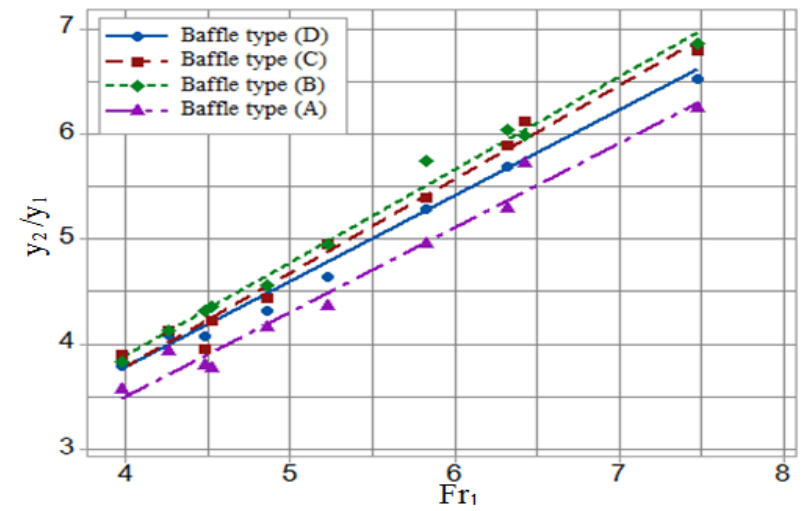

Fig. 9. Sequent depth ratio versus $\mathrm{Fr}_{1}$ for baffle models (A, B, $\mathrm{C}$ and $\mathrm{D})$ at slope (-0.06).

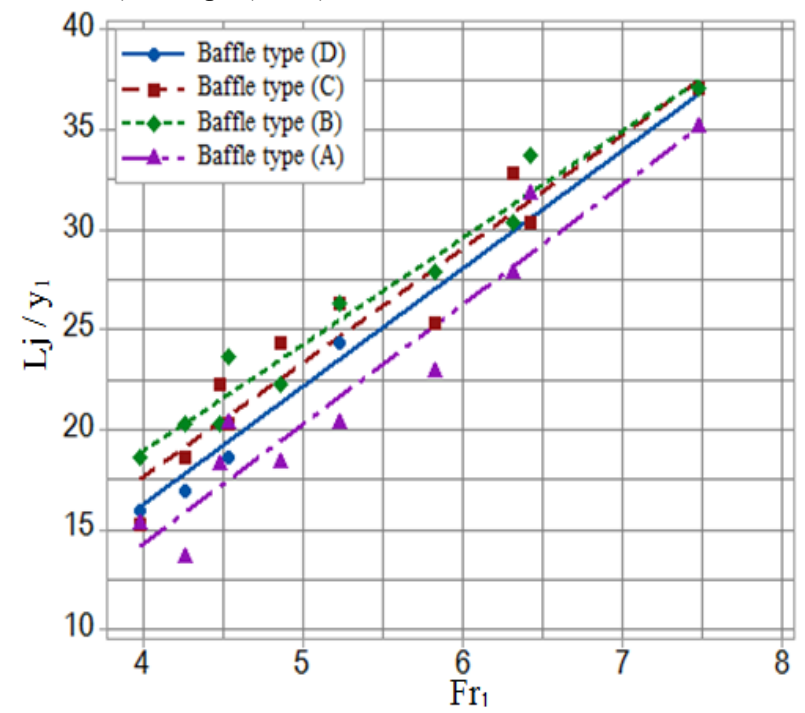

Fig.10. Length of jump ratio versus $\mathrm{Fr}_{1}$ for baffle models (A, $\mathrm{B}, \mathrm{C}$ and D) at slope (-0.06).

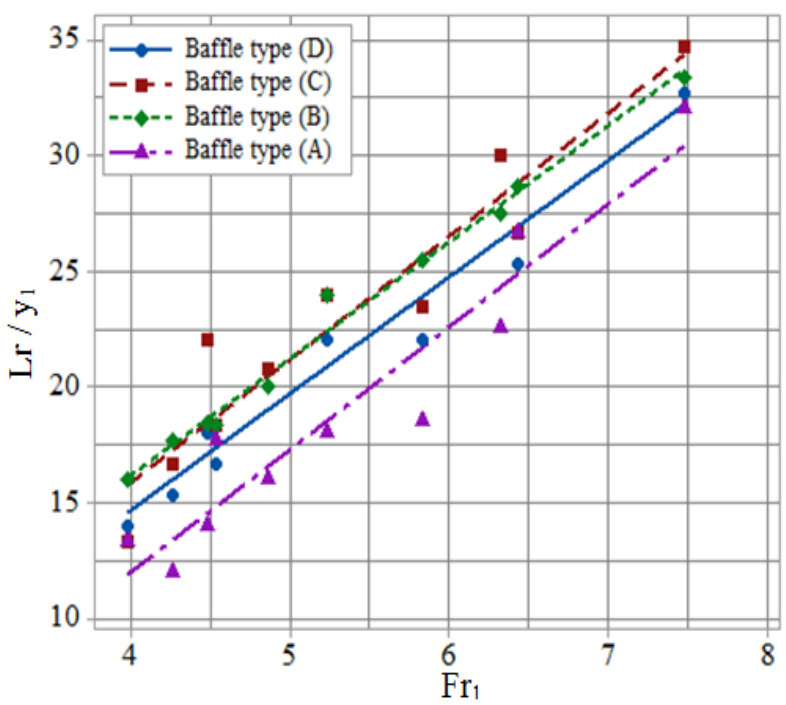

Fig.11. Length of roller ratio versus $\mathrm{Fr}_{1}$ for baffle models (A, B, C and D) at slope (-0.06).

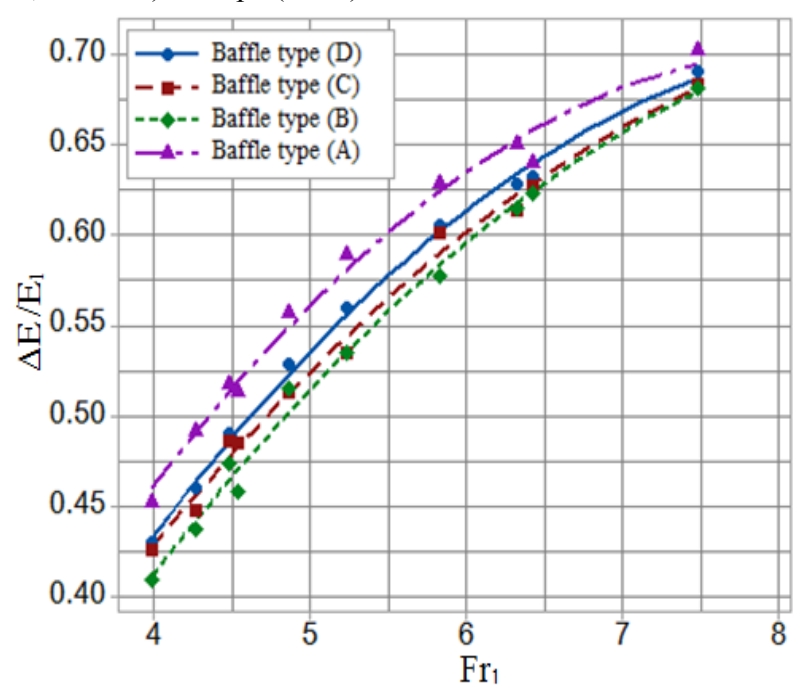

Fig.12. Energy dissipation ratio versus $\mathrm{Fr}_{1}$ for baffle models (A, B, C and D) at slope (-0.06).

Table (2). Values of $(\dot{x} / \mathrm{b})$ ratio for different slopes.

\begin{tabular}{|c|c|c|c|c|}
\hline No. & Bed slopes & $(\dot{\mathrm{x}}) \mathrm{mm}$ & $\begin{array}{c}(\mathrm{b}) \\
\mathrm{mm}\end{array}$ & $(\dot{\mathrm{x}} / \mathrm{b})$ \\
\hline 1 & 0 & 30 & 15 & 2 \\
\hline 2 & -0.03 & 30 & 15 & 2 \\
\hline 3 & -0.045 & 45 & 15 & 3 \\
\hline 4 & -0.06 & 90 & 15 & 6 \\
\hline
\end{tabular}

\subsubsection{Double row of baffle blocks}

The efficiency of stilling basin increased when the baffle blocks arranged as double row, the distance between first and second row represented by the ratio $(\dot{\mathrm{x}} / \mathrm{b})$, where $(\dot{\mathrm{x}})$ 
and (b) represent the longitudinal distance between baffles rows and the length of baffle respectively. The ratio $(\dot{\mathrm{x}} / \mathrm{b})$ does not the same for all slopes (increase with increasing the adverse slope) due to the effects of the weight of water in adverse slope, table (2) shows the variation of $(\dot{\mathrm{x}} / \mathrm{b})$ ratio with bed slopes, also Figure (13) show the hydraulic jump at stilling basin with double row of model (D).

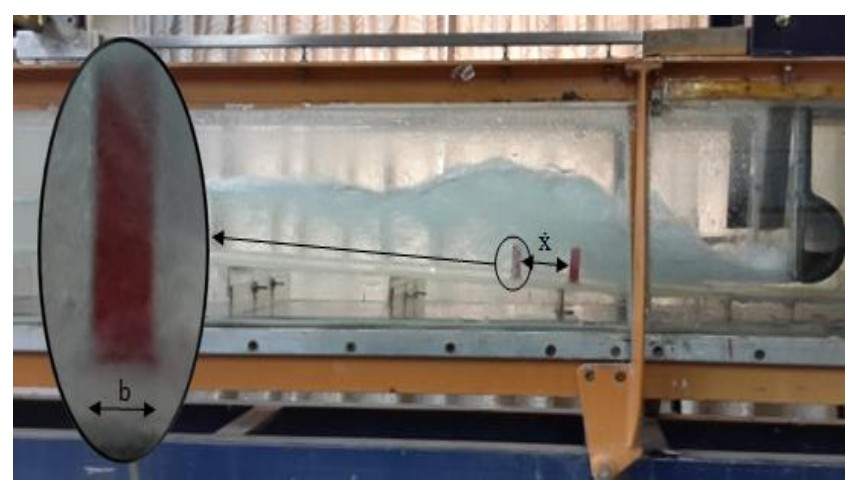

Fig.13. Hydraulic jump at stilling basin with double row of model (D).

\subsection{Effects of bed conditions on hydraulic jump characteristics}

Characteristics of hydraulic Jump changed when bed conditions varied such as using a smooth bed or using baffle blocks as single or double row with various bed slopes. The results of hydraulic Jump on a smooth bed case compared with that for the cases of single row for baffle models (A and D) and the double row of model (D), all these cases applied at slopes $(0,-0.03,-0.045$, 0.06).

\subsubsection{Sequent depth ratio}

Experimental results for a certain slope show a reduction in the ratio of $\left(\mathrm{y}_{2} / \mathrm{y}_{1}\right)$ for the case of double baffle model (D) when compared with results for cases of smooth bed, single row of model (D) and single row of model (A) as shown in Figure (14), the comparison for different cases (at adverse slope (-0.06)) summarized in table (3). Also, using the double baffle model (D) at adverse slope (0.06 ) instead of baffle model (A) at the horizontal slope cause a reduction in the ratio of $\left(\mathrm{y}_{2} / \mathrm{y}_{1}\right)$, the average reduction in this case reaches to about $18.3 \%$. The reduction in the ratio $\left(\mathrm{y}_{2} / \mathrm{y}_{1}\right)$ when the second row of model (D) used is due to the obstruction of the water particles by the second row and make them to circulate with limited zone, therefore reducing the tailwater is essential to prevent formation of submerged jump.

Using single baffle model (D) at adverse slope ($0.06)$ gives a good reduction in sequent depth ratio when compared with the case of baffle model (A) at the horizontal slope, the average reduction in this case reaches to about $10.7 \%$. The reduction in the ratio $\left(\mathrm{y}_{2} / \mathrm{y}_{1}\right)$ lead to reduce in height of the side wall of stilling basin, consequently the cost of construction of stilling basin is reduced.

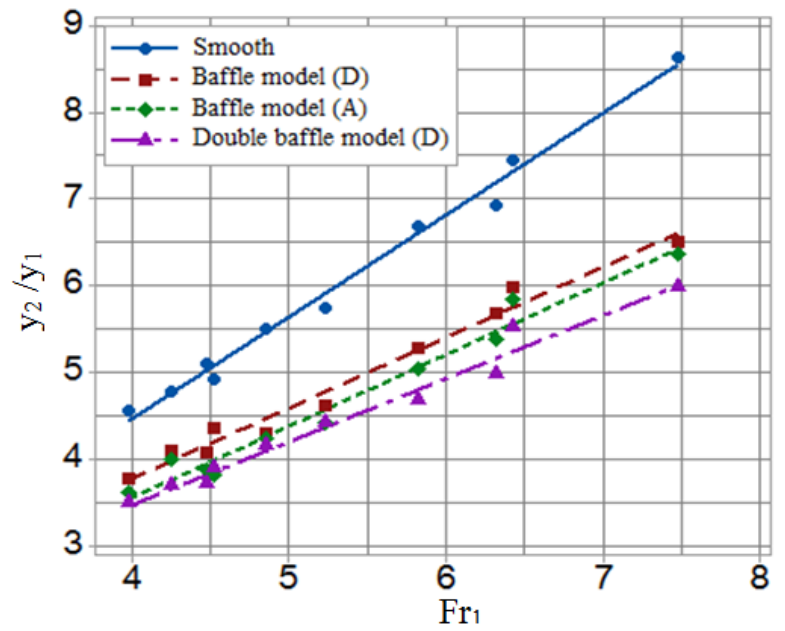

Fig.14. Variation in ratio $\left(\mathrm{y}_{2} / \mathrm{y}_{1}\right)$ due to the change in the bed conditions on slope $=(-0.06)$.

Table (3). Reduction in $\left(\mathrm{y}_{2} / \mathrm{y}_{1}\right)$ for different cases on slope ($0.06)$.

\begin{tabular}{|c|c|c|}
\hline \multicolumn{2}{|c|}{ Bed condition } & \multirow{2}{*}{$\begin{array}{c}\text { Reduction } \\
\text { in }\left(\mathrm{y}_{2} / \mathrm{y}_{1}\right)\end{array}$} \\
\hline Case 1 & Case 2 & $26 \%$ \\
\hline Smooth & Double & $26 \%$ \\
\cline { 1 - 1 } \cline { 1 - 1 } Single model (D) & model (D) & $8.6 \%$ \\
\cline { 1 - 1 } \cline { 1 - 1 } Single model (A) & & $4.4 \%$ \\
\hline
\end{tabular}

\subsubsection{Length of jump ratio}

The length of Jump ratio $\left(\mathrm{Lj} / \mathrm{y}_{1}\right)$ change when the status of basin bed is changed, the results for a certain slope show a reduction in the ratio of $\left(\mathrm{Lj} / \mathrm{y}_{1}\right)$ for the case of double baffle model (D) when compared with results for cases of smooth bed, single row of model (D) and single row of model (A) as shown in figure (15), the comparison for different cases (at adverse slope (-0.06)) summarized in table (4). Also, using the double baffle model (D) at adverse slope (-0.06) instead of baffle model (A) at the horizontal slope cause a reduction in the ratio of $\left(\mathrm{Lj} / \mathrm{y}_{1}\right)$, the average reduction in this case reaches to $38.1 \%$. The reduction in the ratio of $\left(\mathrm{Lj} / \mathrm{y}_{1}\right)$ when the second row of model (D) used is due to the obstruction of the water particles by the second row and restrict its motion, therefore the jump does not extend towards downstream.

Using baffle model (D) at adverse slope (- 0.06) gives a good reduction in length of jump ratio when compared with the case of baffle model (A) at the horizontal slope, this reduction in the ratio $\left(\mathrm{Lj} / \mathrm{y}_{1}\right)$ reaches to about $29.1 \%$, the reduction in length of jump ratio $\left(\mathrm{Lj} / \mathrm{y}_{1}\right)$ means a reduction in the length of stilling basin, consequently the cost of construction of stilling basin is reduced. 


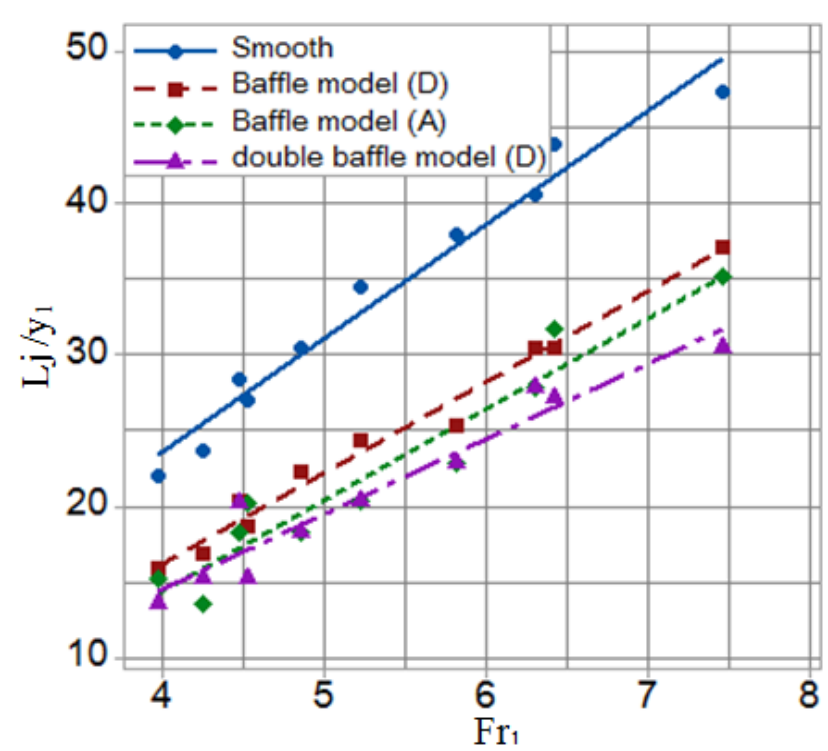

Fig.15. Variation in ratio $\left(\mathrm{Lj}_{\mathrm{j}} / \mathrm{y}_{1}\right)$ due to the change in the bed conditions on slope $=(-0.06)$.

Table (4). Reduction in $\left(\mathrm{Lj}_{\mathrm{j}} / \mathrm{y}_{1}\right)$ for different cases at adverse slope (-0.06).

\begin{tabular}{|c|c|c|}
\hline \multicolumn{2}{|c|}{ Bed condition } & \multirow{2}{*}{$\begin{array}{l}\text { Reduction } \\
\text { in }\left(\mathrm{Lj} / \mathrm{y}_{1}\right)\end{array}$} \\
\hline Case 1 & Case 2 & \\
\cline { 1 - 1 } Smooth & Double model & $37 \%$ \\
\cline { 1 - 1 } \cline { 1 - 1 } Single model (D) & (D) & $12.7 \%$ \\
\cline { 1 - 1 } Single model (A) & & $5.6 \%$ \\
\hline
\end{tabular}

\subsubsection{Energy dissipation ratio}

The energy dissipation ratio of hydraulic jump change when the bed status is changed, as mentioned previously using smooth stilling basin with adverse slope $(-0.06)$ instead of horizontal smooth bed caused a reduction in the energy dissipation ratio, but using baffle block convert this reduction to gain in the energy dissipation ratio.

The experimental results show that the average gain in the ratio of $\left(\Delta \mathrm{E} / \mathrm{E}_{1}\right)$ reaches to about $10.7 \%$ when double baffle of model (D) at slope adverse $(-0.06)$ is used instead of horizontal smooth bed. Also, experimental results for a certain slope show an increasing in the ratio of $\left(\Delta \mathrm{E} / \mathrm{E}_{1}\right)$ for the case of double baffle model (D) when compared with results for cases of smooth bed, single row of model (D) and single row of model (A) as shown in Figure (16), the comparison for different cases (at adverse slope (-0.06)) summarized in table (5). The additional impact action that produce from the second row of baffle blocks cause the increasing in ratio $\left(\Delta \mathrm{E} / \mathrm{E}_{1}\right)$, also the trapezoidal shape of the baffle model (D) makes the water particles to impact with other and loses its energy.

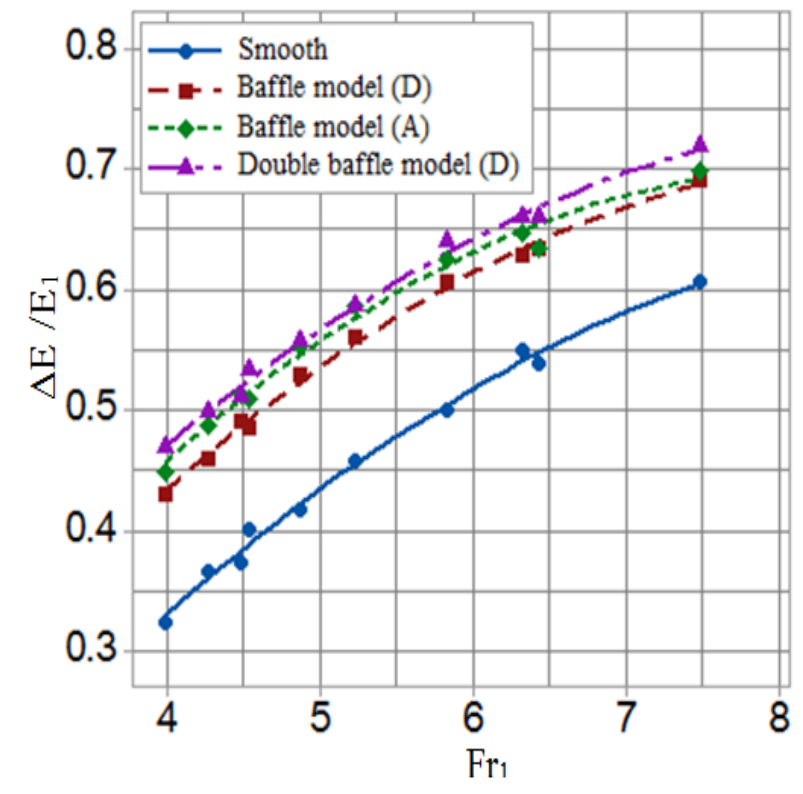

Fig.16. Variation in ratio $\left(\Delta \mathrm{E} / \mathrm{E}_{1}\right)$ due to the change in the bed conditions at slope $=(-0.06)$.

Table (5). Gain in $\left(\Delta E / E_{1}\right)$ for different cases at adverse slope ($0.06)$.

\begin{tabular}{|c|c|c|}
\hline \multicolumn{2}{|c|}{ Bed condition } & \multirow{2}{*}{ Gain in } \\
\cline { 1 - 1 } Case 1 & Case 2 & $\left(\Delta \mathrm{E}_{\mathrm{E}} \mathrm{E}_{1}\right)$ \\
\hline Smooth & Double model & $28.6 \%$ \\
\cline { 1 - 1 } Single model (D) & (D) & $5.7 \%$ \\
\cline { 1 - 1 } Single model (A) & & $2.2 \%$ \\
\hline
\end{tabular}

\section{Conclusions}

- The hydraulic jump in the stilling basin with a single row of model (D) has a less ratio of $\left(\mathrm{Lj} / \mathrm{y}_{1}\right),\left(\mathrm{y}_{2} / \mathrm{y}_{1}\right)$ and $\left(\mathrm{Lr} / \mathrm{y}_{1}\right)$ and a high ratio of $\left(\Delta \mathrm{E} / \mathrm{E}_{1}\right)$ when compared with models (B) and (C), therefore model (D) represents the best trapezoidal model and used with model (A) on other slopes to show their effects when bed slopes are changed.

- In the arrangement of baffle blocks with double row the distance between the first and second rows ( $\dot{\mathrm{x}})$ does not the same for all slopes, this distance increase with increasing the adverse slope.

- At adverse slope (-0.06) the average reduction in $\left(\mathrm{y}_{2} / \mathrm{y}_{1}\right)$ ratio and $\left(\mathrm{Lj} / \mathrm{y}_{1}\right)$ ratio reach to about $26 \%$ and $37 \%$ respectively when the double baffle model (D) is used instead of smooth bed.

-The average reduction in the ratio $\left(\mathrm{y}_{2} / \mathrm{y}_{1}\right)$ reaches to about $10.7 \%$, while the average reduction in the ratio $\left(\mathrm{Lj} / \mathrm{y}_{1}\right)$ reaches to about $29.1 \%$ when the baffle model (D) at adverse slope (- 0.06) used instead of baffle model (A) at horizontal bed.

-The average reduction in $\left(\mathrm{y}_{2} / \mathrm{y}_{1}\right)$ ratio reaches to $18.3 \%$, while the average reduction in $\left(\mathrm{Lj} / \mathrm{y}_{1}\right)$ ratio reaches to $38.1 \%$ when the double baffle model (D) at adverse slope $(-0.06)$ used instead of the horizontal smooth bed.

- At adverse slope (-0.06) the average gain in $\left(\Delta \mathrm{E} / \mathrm{E}_{1}\right)$ ratio reaches to about $28.6 \%$ when the double baffle 
model (D) is used instead of smooth bed.

-The energy dissipation ratio $\left(\Delta \mathrm{E} / \mathrm{E}_{1}\right)$ reduced when the adverse slope used instead of the horizontal slope, but using the double row of baffle model (D) at adverse slope increasing the efficiency of stilling basin and convert the reduction in energy dissipation to gain, the average gain in ratio $\left(\Delta \mathrm{E} / \mathrm{E}_{1}\right)$ reach to about $10.7 \%$ when the double baffle of model (D) at slope $(-0.06)$ is used instead of horizontal smooth bed.

\section{References}

1. S.K. Gupta, R. C. Mehta, and V. K. Dwivedi, Procedia Engineering 51, 529 - 537(2013).

2. W. H, Hager, Vol.8, Zurich, Switzerland, Swiss Federal Institute of Technology (ETH), 10-18 (1992).

3. V.T.Chow, McGraw-Hill Book Company,(1959).

4. N. Rajaratnam, J. Irrig. and Power, India, 23 (2), 137-149(1966).

5. K.M. Abdul, and S. Rajagopal, J. Irrig. Pwr. India, 29, 77- 82. (1972)

6. J. A. Mccorquodale, and M. S. Mohamed Journal of Hydraulic Research Vol. 32, 1, 119-130. (1994).

7. H. K. Shayan, and J. Farhoudi, Journal of Hydraulic Structures Vol. No.II University of Tehran, Tehran, Iran.( 2013).

8. M. S. Bateni, and F. Yazdandoost, Proceedings of the Institution of Civil Engineers, Water Management 162 Issue WM5 Pages 321-327, research gate. (2009).

9. M. k.Beirami, nd M.R. Chamani, , "Can. j. Civil. Eng. 37, 535-543 by NRC Research press(2010).

10. M. H.Chaudhry, "Open-Channel Flow" (Second Edition), University of South Carolina, Springer, (2008).

11. A. J.Peterka, (Eighth Edition) United States Department of the Interior, Bureau of Reclamation (1984).

12. A. Bestawy, Asian Transactions on Engineering Volume 03, Issue 01(2013). 